\title{
The Fertilizer Industry
}

\author{
By Wm. H. Waggaman \\ SCIENTIST IN FERTILIZER INVESTIGations, BUREAU OF SOILS, Washington, D. C.
}

$I^{\top}$ $N$ THE PURCHASE of no other commodity offered on the market to-day is the consumer more dependent upon chemistry to protect him against fraud than he is in the buying of fertilizer. Before the advent of state fertilizer control enormous tonnages of relatively valueless materials were sold at a high price on the basis of an attractive name, a rich brown color and a strong disagreeable odor, and even up to the present time certain brand names persist which give the impression that the product offered has peculiar properties or mysterious power rendering it particularly well adapted for giving bumper yields of special crops.

Chemical control was first inaugurated in this country by the Connecticut Experiment Station in 1876, and laws were - passed requiring the fertilizer manufacturer to state on his containers the actual quantities of fertilizer ingredients present in his goods. The other experiment stations soon recognized the advantage of such regulations and chemical control is now in effect in almost every state, and the guaranteed composition of fertilizer mixtures are so constantly checked up in laboratories of the state chemists that it is practically impossible for an unprincipled manufacturer to perpetrate a flagrant fraud upon the consumer. Chemical control, therefore, has proved a boon both to the reputable manufacturer and his customer by forcing the dishonest dealer out of business and increasing the efficiency of factory and field practice. It has also educated the farmer so that he is more familiar with the actual value of the various fertilizer ingredients, and brands with alluring titles no longer have the same psychological effect as of old. He wants definite assurance and actual proof that "Excelsior" contains something more than excellent filler, that "Champion" has the substance to deliver a real punch in the field, and that "Black Giant" is backed up by something more substantial than an overpowering odor.

$\mathrm{Up}$ until the past few years, however, there was little tendency toward the use of high-analysis fertilizers, owing to two main causes: First, many farmers found it difficult to realize that bulk has little significance and that it was often poor economy to purchase a low-priced fertilizer; second, there were many low-grade materials which for a long time were considered suitable only for fertilizer purposes and though they had unquestionable value as soil amendments it was practically impossible to use them in large quantities for the manufacture of high-grade goods.

\section{The Stimulus of. War}

Conditions, however, are now changing materially. The farmer has learned the significance of potash, nitrogen, and phosphoric acid, and realizes that more labor and expense are involved when he handles, hauls, and spreads fertilizers containing low percentages of these ingredients than when he uses smaller quantities of higher grade goods. The producer of low-grade organic ammoniates such as tankage, cottonseed meal, and rendered garbage, has also found that these materials are much more valuable and bring a higher price when put into stock food rather than into fertilizer, and so the withdrawal of large amounts of such products from the fertilizer market has caused the manufacturer to turn to other sources of nitrogen to make up this deficit.
It is a curious paradox, but perhaps a fortunate fact, that so many of the materials necessary in the manufacture of explosives and other instruments of destruction are equally important in the production of fertilizers, to which we must now look to help make up the deficit caused by the ravages of war. The world-wide conflict, either by draining our natural sources of fertilizer materials or by cutting off the supplies normally imported from abroad, stimulated chemical research on methods of producing potash, nitrogen compounds, and phosphoric acid as nothing else would or could. Therefore it may be said that while the recent advances in the production of fertilizers are largely due to chemistry, the rapidity of these advances we chiefly owe to war.

\section{Potash Salts}

Before the war the supplies of potash salts imported into this country from the enormous deposits in Stassfurt, Germany, were more than ample to meet our fertilizer requirements, and the price of these natural salts was so low that little encouragement was offered to develop methods of obtaining potash from domestic sources. Chemical processes for the production or recovery of potash from silicate rocks and organic materials were little known outside of the laboratory, and while patented processes for extracting this fertilizer ingredient from such sources existed the quantity thus produced was inconsiderable when compared to the enormous tonnage annually imported.

With the advent of war, however, conditions completely changed. Our chief source of potash was suddenly and completely shut off and the spectacular rise in the price of this material rendered it economically impossible to use more than the smallest quantities in mixed fertilizers. Even then the limited supplies on hand were soon exhausted and we were confronted with the possibility of a serious curtailment in our agricultural output.

Chemistry was called upon to help out in this real emergency and nearly every possible source of potash, both organic and inorganic, was given consideration and close study. The feverish energy expended in research was not long in bearing fruit. Substantial quantities of potash were extracted from the mineral alunite, of which we have large deposits in southern Utah. Improved processes for recovering this fertilizer ingredient from such organic sources as kelp and sugar-beet waste were devised. Chemical investigations established the fact that we possessed in our blast furnace and cement industries immense potential sources of soluble or available potash and the latter industry was soon contributing a considerable annual tonnage. Finally the recovery of potash from the brines of certain saline lakes in Nebraska and California was found to be economically feasible and when the armistice was signed a number of plants were turning out potash from this source.

Within four years an American potash industry was built up where none previously existed and in 1918 we turned out 50,000 tons of actual potassium oxide or about one-fifth of that normally consumed for agricultural purposes. While it is generally believed that this industry is not yet sufficiently firmly established to meet foreign competition unless it has a protective tariff, the potash producers claim that such pro- 
tection will be needed for a limited time only or until they have perfected or increased the efficiency of their chemical processes.

Whether or not the United States continues to produce a large tonnage of potash is an open question, but we have learned that we have resources of this fertilizer ingredient and in case of emergency we know where and how to get it.

\section{Nitrogen Carriers}

The production or recovery of compounds of nitrogen by chemical processes is one of prime importance to the fertilizer industry. Throughout the war difficulty of obtaining adequate quantities of fixed nitrogen caused the allied nations considerable alarm. None of the large nations, with the possible exception of Germany, was producing sufficient amounts to meet its requirements and the imports of Chilean nitrate upon which they were so largely dependent were always threatened by the menace of the submarine. The withdrawal of much of our supply of organic ammoniates for stock feeding purposes had already placed an added strain on our normal output of nitrogen products, and this, coupled with the sudden demands of war, brought us face to face with the danger of a shortage for fertilizer purposes.

In order to enhance our own nitrogen output every effort was made to increase our production of ammonium sulfate by the replacement of the old "beehive" coke ovens with the by-product type, and so vigorous and successful were these efforts that within a period of two years our output of this product was pushed from 197,128 tons to 348,654 tons annually. Thus an almost criminal industrial waste which had been going on for many years was materially reduced. Nothing but the emergency of war could have brought about this rapid increase in the recovery of the by-products of bituminous coal.

But our own supply of nitrogen products was still far short of that required. Moreover, the importance of making ourselves independent of foreign sources gave an added stimulus to researches for the synthetic production of nitrogen compounds from the inexhaustible supply in the air. The cyanamide process was the only one of these methods which had been commercially successful in America and this was not in operation in the United States. The knowledge and advice of the foremost chemists and technologists in the country were sought, and no effort and expense spared to solve this problem so vital to the public safety. While these investigations are still being continued, much progress has been made, particularly on the Haber process, of manufacturing ammonia, and there is little doubt that within the next decade we will be producing synthetic nitrogen compounds at a price sufficiently low to compete with the natural nitrate deposits of South America and the ammonium sulfate obtained from our by-product coke and gas plants.

\section{Phosphoric Acid and Phosphates}

While chemical processes were used in the manufacture of phosphatic fertilizers long before they were employed in the production of either of the other two fertilizer ingredients, it was not until about the middle of the last century that we advanced beyond the application of natural sources of phosphoric acid.

In 1840 Liebig and Lawes proposed treating bones and phosphate rock with sulfuric acid in order to render the phosphate water-soluble and more quickly available to crops. So successful has this simple chemical process proved that it is now almost universally employed, and fully 50 per cent of the sulfuric acid produced in this country is used in the manufacture of acid phosphate.

Basic phosphatic slag was first produced in 1875 , and while merely a by-product obtained in the manufacture of steel by the basic Bessemer process, it has been a very valuable supplement to acid phosphate. The discovery of basic slag was largely due to an intimate knowledge of the chemistry of iron and a close study of the nature and properties of its impurities.

When war was declared the demand for sulfuric acid so increased that we were hard pressed to produce sufficient quantities for both munitions and fertilizer purposes, and this led to the investigation of other methods of producing soluble and available phosphates. The indications are that at least one of these general processes is going to play an important part in future fertilizer practice. The pyrolytic method of producing phosphoric acid, wherein mixtures of phosphate rock, silica, and coke are heated at high temperatures and the phosphoric acid distilled off and collected, has already proved commercially successful, and though most of the acid thus produced is consumed in the manufacture of baking powder chemicals and other relatively high-priced phosphate products, this process has so many advantages over the sulfuric acid method where cheap power and fuel are available that there is little question it will eventually be widely employed in the production of phosphate fertilizers. By the use of this process many deposits of low-grade rock that are considered unfit for the manufacture of acid phosphate will be made available, and the "run of mine" phosphate can be used directly without the expense and losses entailed in the washing and screening processes now so extensively employed. Moreover, the fact that the pyrolytic process yields a concentrated product which can stand the cost of long shipments may make it possible to develop more quickly our immense reserves of phosphate rock in the far west that have as yet been exploited to only a limited extent because of their distance to the fertilizer market. The success of this method, however, depends on close chemical control, and a careful study of the-reactions that take place between phosphate of lime, silica, iron, and aluminium at high temperatures under both reducing and oxidizing conditions.

\section{Concentrated Fertilizers}

The trend of the fertilizer industry to-day is toward the manufacture and use of more concentrated products. While increased freight rates and higher labor costs are partially responsible for this movement, a better understanding of the chemistry of fertilizers and the economies effected by the employment of new and improved processes are the main causes for our advance. Along with the direct manufacture of phosphoric acid and the synthetic production of ammonia must come the wider use of definite and relatively pure chemical compounds for fertilizer purposes, for these two fertilizer ingredients must be combined with a base and an acid, respectively, in order to handle, ship, and distribute them successfully. The practice in the past has been to partially neutralize phosphoric acid with lime and to fix ammonia with sulfuric acid in the form of ammonium sulfate, but such procedure appears foolishly extravagant when we consider that neither of these materials adds anything to the value of the product. The logical procedure is to combine the phosphoric acid with ammonia to form ammonium phosphate or with potash as potassium phosphate, and where both ammonia and nitric acid are produced combine them to form ammonium nitrate. In every case a salt is obtained wherein both the acid and the base contribute their share to the market value of the fertilizer.

It is recognized, of course, that great care must be exercised in distributing such concentrated fertilizer compounds in the field, and it may be necessary or advisable to dilute such products before they are actually applied to the soil, but this can be done near the point of consumption and the needless 